\title{
PRIMARY HYPERPARATHYROIDISM \\ DETECTED IN A PATIENT UNDERGOING TWO PRIOR THYROIDECTOMIES \\ FOR FOLLICULAR THYROID CARCINOMA: A CASE REPORT
}

Gulsah Elbuken ${ }^{1}$, Zehra Gulciftci- Dagcı², Omer Ozcaglayan ${ }^{3}$, Ayşe Tuba Tonbul ${ }^{4}$, Neslihan Soysal-Atile ${ }^{5}$, Sayid Zuhur ${ }^{1}$

1 Namik Kemal University Medical School, Dept of Endocrinology and Metabolism, Tekirdag, Turkey

2 Tekirdag Govt. Hospital, Dept of Pathology, Tekirdag, Turkey

3 Namik Kemal University Medical School, Dept of Radiology. Tekirdag, Turkey

4 Namik Kemal University Medical School, Dept of Nuclear Medicine, Tekirdag, Turkey

5 Tekirdag Govt. Hospital, Dept. of Endocrinology and Metabolism, Tekirdag, Turkey

\section{Introduction:}

\section{Case Presentation:}

Table and Figures:
Primary hyperparathyroidism (PHPT) is usually characterized by overproduction of parathormone (PTH) due to a solitary parathyroid adenoma. Its treatment involves surgical removal of the solitary adenoma or hyperplastic parathyroid glands that secrete PTH. Medical treatment options are used for patients with conditions that preclude surgical operation.

A 57-year-old female patient underwent left total and right subtotal thyroidectomy operations on 18.05.2009 for multinodular goiter. Pathological examination revealed a $5.5 \mathrm{~cm}$ follicular carcinoma in the left lobe. Lymphovascular invasion of the tumor was present. On 30.06.2009, she underwent completion thyroidectomy, and central compartment and ipsilateral lateral cervical lymph nodes dissection. Subsequently received ablative therapy with radioactive iodine (RAl) at a dose of $150 \mathrm{mCi}$. Elevated calcium and reduced phosphorus levels were found during her follow-up visits (Table). While the findings of several tests were consistent with primary hyperparathyroidism, only a slightly echoic, wellcircumscribed lesion $(5 \times 5 \times 11 \mathrm{~mm})$ located close to the former place of the inferior pole of the right thyroid gland was detected by neck ultrasound images and its vascularization was shown by Doppler ultrasound (Figure-1). However, no increase in activity or uptake was observed during parathyroid scintigraphy (Figure-2) and neck CT did not show a tumor mass formation.

Her serum calcitonin level was normal (Table). The possibility of a thyroid medullary carcinoma was excluded by reexamining of her paraffin-embedded thyroid blocks. The patient who already had undergone two major surgeries and one course of RAI treatment refused another neck operation. Thus, treatment with Cinacalcet was initiated. Calcium values returned to normal after the treatment (Table).

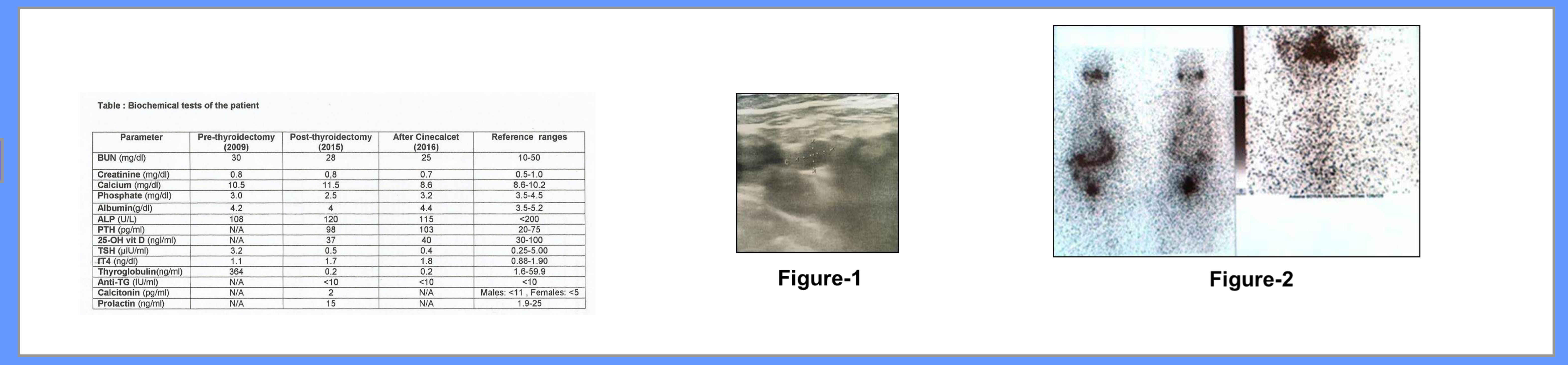

Conclusion:

PHPT in the presence of thyroid follicular carcinoma is a rare occurrence. Non-visualization of parathyroid tissue by imaging studies in a patient with two prior thyroidectomy operations and RAl therapy makes our case quite an interesting one. Cinacalcet therapy is a good therapeutic option to control calcium levels in cases where excessive secretion of PTH cannot be achieved by surgical intervention. 